\title{
Habitat type and altitude work in tandem to drive the community structure of dung beetles in Afromontane forest
}

by Stanbrook, R., Wheater, C.P., Harris, W.E. and Jones, $\mathrm{M}$.

Copyright, publisher and additional information: .This is the authors' accepted manuscript. The published version is available via Springer.

Please refer to any applicable terms of use of the publisher

DOI link to the version of record on the publisher's site University 
1 Title: Habitat type and altitude work in tandem to drive the community structure of dung beetles in

2 Afromontane forest

3

4

$5 \quad$ Roisin Stanbrook ${ }^{1,2^{*}}$, C. Philip Wheater ${ }^{2}$, W. Edwin Harris ${ }^{2,3}$ and Martin Jones ${ }^{2}$

6

$7 \quad{ }^{1}$ Department of Biology, University of Central Florida, Orlando, USA, 32816-2368

8

$9 \quad{ }^{2}$ Faculty of Science and Engineering, Manchester Metropolitan University, Manchester, UK, M1 5GD

10

$11{ }^{3}$ Crop and Environment Sciences, Harper Adams University, Edgmond, UK, TF10 8HY

12

*Corresponding author.E-mail: roisin.stanbrook@ucf.edu

Orchid iD: https://orcid.org/0000-0002-6753-9751

Abstract

Introduction

Dung beetles are a species group highly recognized for their sensitivity to anthropogenically induced change. There are few studies of the dung beetle communities found in Afromontane forests despite these forests forming part of a global hotspot of biodiversity.

\section{Methods}

We used comparisons of diversity to investigate the effect of habitat and altitude on the species composition of Scarabaeidae dung beetles in six Afromontane habitat types and identified indicator species associated with each forest type.

\section{Results}

A total of 8020 individuals from 34 species belonging to 16 genera were captured at twelve transect locations across a $1.5 \mathrm{~km}$ altitudinal gradient. All indices measuring diversity and dominance showed significant differences between forest types with little overlap in the species composition detected in each. 
Altitude was negatively correlated with dung beetle abundance, species richness, and diversity (abundance: $\mathrm{R}^{2}=-0.392, P=<0.001$, richness: $\mathrm{R}^{2}=-0.779, P=<0.001$, diversity: $\mathrm{R}^{2}=-0.735, P=<0.001$ ), and there were also significant differences in abundance, species richness and diversity between altitude zones. Eight indicator species were identified for potential use in future conservation management or monitoring programs.

Discussion

This study found no significant relationship between species richness and forest type but an interaction between the two factors. Altitude in conjunction with forest type are the main factors in shaping dung beetle species composition in this Afromontane forest. Our results suggest the most important characteristic for determining community structure was mean canopy cover per forest type. Results from a previous short study conducted in 1974 indicate while there was significant overlap between dung beetle species caught 40 years ago and the present day there were also seven species which were absent. All seven of these species have climatic distributions centered around the wet highlands of East Africa and further work is urgently required to understand why these species are no longer detectable.

Implications for insect conservation

Our results have important conservation implications as they underscore the importance of preserving forest heterogeneity to maintain maximum dung beetle diversity within mountain ecosystems. The identified differences in dung beetle diversity between forest types and the high turnover of dung beetle species between altitude zones should heighten the importance for instigating future Scarabaeidae conservation initiatives in Afromontane regions.

Keywords: Afromontane forest, Altitude gradient, Beta diversity, Dung beetles, Indicator species

\section{Declarations}

Funding

The authors received no funding for this work

\section{Conflicts of interest/Competing interests}

59 The authors have declared that no competing interests exist. 


\section{Availability of data and material (data transparency)}

62 The authors confirm that the data supporting the findings of this study are available within the article

63 (and/or) its supplementary materials.

\section{Acknowledgements}

Data were collected with the authorization and help of the Kenya Wildlife Service under research permit number NACOSTI/P/15/0573/3206. We thank Laban Njoroge at the National Museums Kenya for the use of their facilities for storage and identification. We also thank Darren Mann, Oxford University Museum of Natural History and Phillipe Moretto for their assistance with species identifications.

\section{Introduction}

The high species richness and diversity found in tropical montane habitats are the result of three main factors: (1) the impact of climatic and geological history on biotic evolution; (2) species adaptations to environmental constraints; and (3) the continuous dispersal of fauna and flora over time. The alteration of very cold and wet and then warm and dry periods in the Pleistocene epoch encouraged the formation of refuges (Fjeldsa and Lovett 1997), which served as shelters for a rich diversity of species, and also sources for dispersion of biota to neighboring areas as warming of the climate allowed species ranges to expand. In East Africa these refuges are now mostly confined to the forest archipelago of mountains dotted from southern Tanzania to the Bale mountains in Ethiopia (Hedburg 1969). Altitudinal differences within mountain forests have also made for very varied climates and this wide diversity of climates combined with local differences owing to geomorphological, edaphic and plant cover have given rise to a range of microclimates which help generate a wide range of specific niches (Coe 1969).

The refugia hypothesis (Fjeldsa \& Lovett, 1997) suggests that differences in species diversity and occurrence between isolated patches are the result of allopatric speciation. Changes in species distribution 
across environmental gradients may reflect habitat specialization by constituent species (Laurance et al. 2011) and limiters such as thermal tolerance and resource availability restrict niche space and determine the spatial extent of species distributions and successional patterns. One well-studied aspect of patterns in spatial biodiversity is the species turnover that occurs along altitudinal gradients, especially those which occur in tropical montane habitats (Escobar et al. 2005). These changes may arise over small spatial extents due to the close proximity of different habitats and, as a consequence, communities may differ dramatically in species composition over small distances, for example between valleys or mountain peaks (Jankowski et al. 2009).

Tropical montane forests constitute one of the biologically richest environments on earth (Aldrich et al. 1997) and often contain a large number of endemic species (Merckx et al. 2015). However, African montane (Afromontane) forests and their associated biota are poorly studied despite being important hotspots of terrestrial biodiversity (Mittermeier et al. 2011; CEPF 2012). In Kenya, Afromontane ecosystems are estimated to cover $7.4 \%$ (58 Mha) of the terrestrial area and montane forests represent $57 \%(740,000 \mathrm{ha})$ of forest cover (Paron et al. 2013). The majority of the studies that assess Afromontane biotic distributions in East Africa pertain to vertebrates (Martin et al. 2015; Rovero et al. 2016; Stanley and Kihaule 2016) and plants (Nyundo et al. 2006; Eisenring et al. 2016). Little is known about insect diversity of African forests or the factors which may explain their distribution. Invertebrates constitute the bulk of known biodiversity on Earth and dominate virtually every terrestrial ecosystem in terms of species richness, animal biomass, and the provision of essential ecosystem services (Samways 2015). Thus, understanding of the factors influencing invertebrate taxonomic richness and diversity at both local and regional scales is important for conserving biodiversity and for maintaining ecosystem services. Dung beetles are known to represent an important functional component of the animal fauna found in tropical forests (Krell-Westerwalbesloh et al. 2004; Banks et al. 2010) as they provide several key ecological functions such as seed dispersal, parasite suppression and dung removal (Nichols et al. 2008). 
113 A recent global meta-analysis (Nichols et al. 2007) of 26 studies of dung beetle community responses to

114 tropical forest modification and fragmentation showed that dung beetle species richness, abundance, and

115 biomass undergo a gradual decline across a modification gradient from intact tropical forest to clear-cut

116 areas, and as forest fragments became smaller and/or more isolated. Dung beetle communities are very

117 sensitive to changes in abundance of food resources, microclimatic variables and soil characteristics

118 (Hanski et al. 1979; Hanski and Cambefort 1991; Osberg et al. 1994; Pryke et al. 2013). Changes in

119 community organization of dung beetles include alterations in species richness, composition, abundance

120 and guild structure. The physical structure of habitats can be an important determining factor in the

121 composition and distribution of dung beetle assemblages (Davis and Sutton 1998) with a complete species

122 turnover observed across a natural ecotone spanning as little as 100m (Spector and Ayzama 2003).

123 Consequently, dung beetles are a useful indicator group because they reflect structural differences between

124 biotope types (Carpio et al., 2009; Nichols et al., 2013). From savannahs to tropical forests, dung beetles are highly habitat specific and there are distinct communities of beetles associated with forests, edges and pasture habitats. Although some species can utilize more than a single habitat type, certain species may never be found outside their preferred habitat (Scheffler 2005).

A number of factors are thought to influence the spatial pattern of dung beetle species occurrence. Species may have their range restricted by lack of suitable habitat or the decline in quality of existing habitats (Raine and Slade 2019). To date there have been few published studies describing dung beetles in montane regions globally, and their ecology and response to biotic and abiotic factors in African montane forests has seldom been analyzed. The only previous studies assessing dung beetle species across an altitudinal gradient in

134 African mountains are those by Davis et al. (1999) from the Drakensburg mountain range in South Africa and more recently from Mt. Kilimanjaro in Tanzania (Gebert et al. 2019). It is generally accepted that in most invertebrate taxa, species diversity and richness generally decline with increasing altitude (Wolda 1987). However, other studies have also reported mid-elevation peaks in dung beetle species richness (Escobar et al. 2006; Lobo et al. 2007; Herzog et al. 2013; Nunes et al. 2016). Both the African and the 
139 Neotropical studies unravel specific and general patterns that help explain the mechanisms driving the

140 distribution of dung beetles along elevation gradients and with significant implications for biogeographic

141 analysis and conservation priorities. Understanding these patterns is important as there is growing evidence

142 that the effects of climate change are amplified with elevation (Mayor et al. 2017).

144 In this study, we investigate the factors influencing the spatial pattern of dung beetle diversity in Afromontane vegetation. We sampled dung beetles associated with six different forest habitats which are characterized by differences in vegetation types and are located along an altitudinal gradient. We test the hypothesis that altitude and forest type underpin the variation of dung beetle diversity and species composition of dung beetles in Afromontane forests. Our objectives are: 1) to describe dung beetle alpha diversity $(\alpha)$ at the habitat scale; 2$)$ to estimate beta diversity ( $\beta$ ) between elevation zones; and 3 ) to estimate gamma diversity $(\gamma)$ for the whole mountain range. We expected a decrease in species richness with increasing altitude but less species attenuation between forest types. Additionally, we hypothesize that different forest types will have distinct species assemblages from which indicator species can be described. We discuss the implications of these findings for future conservation planning and climate change monitoring within Afromontane forests.

\section{Methods}

\section{Study area}

The study was performed at six locations in the Aberdare National Park (ANP) which is located in the

161 Aberdare mountain range in central Kenya (Figure 1). The mountain range belongs to the northern volcanic 162 sub-region of the eastern Afromontane (EAM) biodiversity hotspot. The hotspot is well known for regional variation in vegetation, rainfall patterns, topography and high levels of endemism across its range (Taylor 2015). The ANP lies to the east of the Gregory Rift Valley and is about $80 \mathrm{~km}$ north of Nairobi and $17 \mathrm{~km}$ 
from Nyeri town $\left(0.4167^{\circ} \mathrm{S}, 36.9500^{\circ} \mathrm{E}\right)$. It is an elongated massif, running approximately north south,

166 parallel to the direction of the Rift Valley, $60 \mathrm{~km}$ to the west of Mt. Kenya. The Aberdare Forest Reserve,

167 a protected area, surrounds the Park. The highest peaks are Oldonyo Lesatima $(4000 \mathrm{~m})$ in the north and Il

168 Kinangop (3906m) in the south. Between these peaks is an extensive moorland region distributed between

$1693300 \mathrm{~m}$ and $3700 \mathrm{~m}$ asl. Like many East African mountains, the Aberdare range was formed by volcanic

170 activity during the Pleiocene and the elongate form of the range is a result of the lava spillage. As a result,

171 the main peaks and ravines of the ANP run in almost straight lines linked by a series of ridges. Topographic

172 and edaphic elements modify the distribution of the six main vegetation types (Bushland, Juniperus

173 dominated forest, Podocarpus dominated forest, Hagenia dominated forest, Bamboo, and Ericaceous moorland) found within the park. The vegetation consists mainly of bamboo, high heath moorland with large areas of open and closed canopy forest. Bushland is prevalent at lower elevations occurring particularly in the Salient sector that extends eastwards from the main peaks.

\section{Bushland Thicket}

Bushlands are open stands of bushes (usually between 3 and $7 \mathrm{~m}$ tall) with a canopy cover of 40 percent or more. Thickets are closed stands of bushes (usually between 3 and $7 \mathrm{~m}$ tall) where the bushes are so densely interlaced that they are impenetrable except along tracks made by animals. Bushlands and thickets are taller than shrublands defined as open or closed stands of shrubs up to $2 \mathrm{~m}$ tall. Dominant vegetation includes Hypoestes forskaolii and Ocimum suave. The grass Cynodon dactylon is common along gametrails (Schmitt 1992).

\section{Juniperus dominated forest}

186 Afromontane single-dominant Juniperus procera forest mostly occurs on the drier slopes of mountains between 1800 and $2900 \mathrm{~m}$, although it sometimes descends to $1000 \mathrm{~m}$ (Bussmann 2006). Dominant species include Juniperus procera, Halleria lucida, Ilex mitis, Kiggelaria africana and Nuxia congesta. 
This forest type is very similar in structure to certain types of Guineo-Congolian rain forest (Kindt et al. 2014) but contains conifer species (Podocarpus) which are absent from this type of rain forest. These forests occur mainly between 1200 and $2500 \mathrm{~m}$ on the slopes of East African mountains.In the ANP this forest type is predominantly found in altitude zone Dominant species include Podocarpus latifolia, Ocotea usambarensis, and Olea capensis.

\section{Afromontane Bamboo}

In East Africa, Sinarundinaria alpina bamboo is mostly found between 2400 and $3000 \mathrm{~m}$, although it ascends to $3500 \mathrm{~m}$ on Mt. Kenya and to $1630 \mathrm{~m}$ Uluguru Mts. (Tanzania). It grows most vigorously on deep volcanic soils and gently slopes where the annual rainfall exceeds $1250 \mathrm{~mm}$. Afromontane bamboo covers almost 65000 ha in the Aberdare mountain Range (Kindt et al. 2014).

\section{Hagenia dominated forest}

Characteristically, Hagenia abyssinica forms almost pure stands of 9 to $15 \mathrm{~m}$ tall in a narrow and often interrupted zone between the montane Ericaceous belt and taller types of Afromontane rain forest. Hagenia abyssinica forest is a climax vegetation type where low night temperatures exclude other trees (Schmitt 1992).

\section{Ericaceous grassland}

Ericaceous vegetation includes well-developed cloud forest of Erica excelsa, and scrub with E. trimera, Stoebe kilimanscharica and Cliffortia nitidula. The altotropical grasslands are dominated by Festuca pilgeri, Koeleria capensis, the C4 grass Andropogon lima (White 1981).

\section{Experimental design}

211 Dung beetles (Coleoptera: Scarabaeidae and Aphodiidae) were collected with pitfall traps baited with 212 elephant dung during three sampling periods; two periods during the wet season during June and August 2132015 , and one during the dry season in late February and early March 2016. Samples collected in both the 214 wet and dry seasons were pooled for analyses. Two $1 \mathrm{~km}$ transects were established in each forest type 215 (Figure 2). We used two transects per forest type as logistics and sampling time were limited by the 
availability of Kenya Wildlife Services security personnel. Eight pitfall traps were used per transect and

217 were baited with $50 \mathrm{~g}$ of elephant dung wrapped in fine gauge mesh netting and left open for four days at

218 each site. Pitfall traps followed the design of Larsen (2005) and spaced $125 \mathrm{~m}$ apart. Traps were emptied and re-baited every 24 hours over a four-day period to provide a total sample of 64 samples per forest type and a total of 384 collections. Once collected, the dung beetles were transferred into a $70 \%$ ethanol solution for preservation and identification. Dung beetles were identified with the help of Darren Mann and Phillipe Moretto using the following keys: Ferreira (1972), Cambefort (1984), D’Orbigny (1911), Zídek \& Pokorný (2004) and Cambefort \& Nguyen-Phung, (1996).

\section{Environmental variables}

An elevation raster layer was created using the banding toolset in ArcMap 10.4. Digital elevation zones at $500 \mathrm{~m}$ intervals were created for the land area within the ANP boundary (Figure 1). Supervised classification using Landsat7 data was then used to create a vegetation layer for the ANP (Figure 2). These layers were used to guide transect placement to ensure transects fell into each forest type and altitude zone. To collect data attributes at each pitfall trap location, a modified version of the Standard International Forestry Resources and Institutions method for vegetation sampling (Ostrom 2008) was used to collect the following data: tree species richness, abundance, herbaceous ground cover, and canopy cover surrounding each trap. Two concentric circles $(1 \mathrm{~m}$, and $10 \mathrm{~m}$ radius) were established around each trap to record these data. Tree seedlings and saplings $(2.5-10 \mathrm{~cm}$ diameter) were counted in the $1 \mathrm{~m}$ radius circle, and mature trees $(>10$ $\mathrm{cm}$ diam.) in the $10 \mathrm{~m}$ radius circle. Tree diameter at breast height (dbh) was measured at $1.3 \mathrm{~m}$ height. Ground vegetation and canopy cover were determined in the $1 \mathrm{~m}$ radius circles. Estimates of percentage ground cover were taken for herbs when individuals were impractical to count. For each trap, the ground vegetation cover was visually scored on five scales as follows: (1) 0-5 percent of the total area of the $1 \mathrm{~m}$ radius circle; (2) 5-25 percent of the total area of the circle; (3) 26-50 percent of the total area of the circle; 
cover was measured at three randomly selected points within the $1 \mathrm{~m}$ radius of every trap using a spherical

242 densitometer.

\section{Data Analyses}

245 Species richness was estimated for each vegetation type using the non-parametric estimator 'Chao1' (Chao 246 1984). Chaol gives an estimate of the absolute number of species in an assemblage based on the number of rare species (singletons and doubletons) in a sample. A Chaol estimate of species richness is recommended for inventory completeness values, completeness being the ratio between observed and estimated richness (Cao and Epifanio 2010; Buddle et al. 2012). Alpha diversity ( $\alpha$-diversity) is the biodiversity within an area, community or ecosystem, and is usually expressed as the species richness of the area. This can be measured by counting the number of taxa (distinct groups of organisms) within the ecosystem (e.g., families, genera, and species). The Shannon Index (H') was used to measure diversity; the index is increased either by having additional unique species, or by having greater species evenness. Pielou's J' was used to estimate species evenness (based on the Shannon Index) that is the relative abundance or proportion of individuals among the species.

\section{Comparison of species richness, diversity and evenness between habitat types}

To test for differences in species richness, abundance and diversity between habitat types and altitude zones we used a Kruskal Wallis test with a post hoc Nemenyi test for multiple comparisons (Zar 2010). We used

260 GLM with Poisson errors and the log link function with Habitat type and Altitude as factors. The $\chi^{2}$ statistic was used to test for significant changes in deviance. We used a Mantel test to evaluate association patterns between distance matrices (Jankowski et al. 2009) using Bray-Curtis dissimilarities for dung beetle species composition, and Euclidean distance matrices for altitudinal distance, canopy cover and ground cover with 999 permutations. 
The Beta.SOR function within the R package Betapart (Baselga 2013) was used to establish the percentage nestedness and turnover between altitude zones and between habitat types. Data were converted from relative abundance data into a presence/absence matrix for use with Sørensen's index. Data were further explored using the beta.core function within Betapart which evaluates the differences in shared species richness between samples.

The Bray-Curtis similarity coefficient was used to determine site similarities based on species abundances. Bray-Curtis cluster analysis (single link) was performed to identify the clustering of habitats into distinct groups. Hierarchical single link clustering takes the similarity matrix as the starting point and successively fuses the samples into groups and the groups into larger clusters, starting with the highest mutual similarities then gradually reducing the similarity level at which groups are formed resulting in a tree diagram or dendrogram plot. Where data conformed to parametric assumptions, such tests were used, otherwise GLMs with appropriate error structure were used. We used R version 3.3.1 (Development Core Team, 2017) to perform all statistical analyses. Mantel tests and calculations of Euclidean distances between altitude pairs were carried out using the 'vegan’ (Oksanen 2015) and 'ecodist (Goslee and Urban 2007) packages.

CLAM analysis (Multinomial Species Classification Method (Chazdon et al. 2011) was used to determine which species are indicators of Afromontane habitat types in the Aberdare mountain range. CLAM is a multinomial model which uses relative abundance of species in two distinguishable habitats. One advantage of CLAM is that the procedure explicitly considers a threshold for rarity, meaning that species that are too rare cannot be classified, and distinguishes species that are generalists from those that demonstrate specificity to one habitat type (Chazdon et al., 2011). An important parameter of the multinomial model is $\mathrm{K}$, which refers to the cut-off point for classifying species according to their habitat type. CLAM was used to classify generalists and specialists into open and closed vegetation types by setting a specialization threshold of $\mathrm{K}=0.667, P=<0.05$ (Bicknell et al. 2014). The model classifies species into one of four groups: (1) Generalist; (2) Habitat A specialist (specialist of open vegetation); (3) Habitat B specialist 
292 (specialist of closed canopy vegetation); and (4) too rare to classify with confidence. Dung beetles were 293 classified as an indicator of a particular habitat type if $\geq 66 \%$ of their occurrences were within that habitat 294 during the sample period.

296 Habitat associations of individual species and functional guilds were ascertained using Pearson Chi-squared residuals and plotted using the hclust function in the Vegan package (Oksanen 2015) to visualize both positive and negative associations and also split dung beetle species into community groups. To see which species were indicative of the six forest types in the ANP, indicator species analysis in the form of association analysis was undertaken using these Pearson residuals. This analysis details which species have significant associations (either positive or negative) for each habitat type based on the co-occurrence of species and uses the probability that the observed frequency of co-occurrence is significantly large and greater than expected (positive association), significantly small and less than expected (negative association), or not significantly different and approximately equal to expected (random association) (Veech 2014).

\section{Results}

A total of 8020 individuals from 34 species belonging to 16 genera were captured at twelve transect locations across a $1.5 \mathrm{~km}$ altitudinal gradient that spanned from 1901 - $3972 \mathrm{~m}$ asl (Figure 1). Eleven species

310 from a previous study conducted by (Davis and Dewhurst, 1993) were recorded plus a further 23 species,

311 three of which were new records for Kenya; Catharsius gibbicollis, Catharsius sesostris, and Hetronitis

312 ragazzi, plus one new species Epidrepanus kenyensis (Roggero et al. 2017). Tunnelling dung beetles constituted the majority of species collected with $82 \%$ of the total versus $15 \%$ for dwellers and just $3 \%$ of rollers. The non-parametric estimate of total species richness was 43 species, indicating that most of the species pool was collected (around 80\%). The most abundant species across all habitats were, Neocolobopterus kivuanus (1362, 17\%), Onthophagus proteus (935, 11.6\%), Onthophagus sp 2, (875, 10.9\%), Onthophagus spurcatus (792, 9.8\%), and Milichus picticollis (587, 7.3\%). These five species 
accounted for $57 \%$ of all individuals collected, demonstrating that habitats were dominated by a few

319 abundant species. An overview of the dung beetle assemblages found in each habitat type is found in

320 Appendix S1.

Variation of dung beetle assemblages in altitude between habitat types and altitude gradients

Each habitat type was described in terms of its diversity, evenness, and estimated richness (Table 1).

Significant positive correlations were found between mean ground cover and dung beetle abundance (rho $=0.40, \mathrm{df}=95,<0.001)$ and species richness $(\mathrm{rho}=0.42, \mathrm{df}=95,<0.001)$. Significant negative correlations were found between mean canopy cover and dung beetle abundance (rho $=-0.24$, $\mathrm{df}=95,<0.01$ ) and species richness ( $r$ ho $=-0.23, \mathrm{df}=95,0.05)$. The overall abundance of individuals, species richness and diversity between habitats did not differ significantly when altitude was also accounted for (Table 2).

Altitude was negatively correlated with dung beetle abundance, species richness, and diversity (abundance: $\mathrm{R}^{2}=-0.392, P=<0.001$, richness: $\mathrm{R}^{2}=-0.779, P=<0.001$, diversity: $\left.\mathrm{R}^{2}=-0.735, P=<0.001\right)$, and there were also significant differences in abundance, species richness and diversity between altitude zones (Figure 3). However, dung beetle abundance, species richness, and diversity did not significantly differ among habitat types (Table 2).

\section{Species composition and habitat specificity}

338 Of the 34-species found in this study, eight (23\%) were deemed indicator species by the Pearson residuals in Chi-squared tests of association - Diastellopalpus johnsonii, Milichus picticollis, Neocolobopterus kivanus, Oniticellus planatus, Onitis anthracinus, Onitis meyeri, Onthophagus miricornis, and Onthophagus proteus. Most habitats had more than one indicator species. The strongest positive associations for Bushland thicket were Milichus picticollis, followed by Diastellopalpus johnsonii and Onitis meyeri (Figure 4) all of which have also been indicated as either generalist or open vegetation 
specialists (Table 3). Bamboo habitat had four indicator species, with Neocolobpterus kivunaus belonging to the Aphodiine having the strongest positive association followed by Oniticellus planatus, Onitis anthracinus, and Onthophagus miricornis. Onthophagus proteus was positively associated with Ericaceous moorland along with Neocolobpterus kivunaus. Hagenia Forest had four indicator species but was most positively associated with Onthophagus miricornis. Two species were positively associated with Juniper forest; the large tunneller Onitis anthracinus and Milichus picticollis, while Podocarpus dominated forest had associated two species; Oniticellus planatus and Onitis anthracinus.

CLAM analysis (Chazdon et al., 2011) further identified which species could be considered forest and open vegetation specialists. Fourteen species (41\%) were classified as open vegetation specialists, ten species $(32 \%)$ were classified as forest specialists and five species (15\%) were found in both open and closed vegetation. Five species (Epidrepanus kenyensis, Catharsisus gibbicollis, Catharsisus setostris, Heteronitis ragazzii, and Heliocopris stroehli) were categorised as too rare to classify as either a generalist or specialist.

\section{Diversity Patterns}

Overall beta diversity was high between all habitat types showing very little species overlap (Table 1). The dendrograms in Figure 5 illustrate the differences in community composition between habitats and altitude zones by measuring the degree of community overlap between habitat types. The axis height of the dendrogram signifies $\beta$ values per habitat type or altitude band. The scale ranges between zero (no overlap) and one (perfect overlap). The Bray Curtis index grouped the species communities in Juniperus and Podocarpus lowland forest types together along with the mid altitude Hagenia dominated forest (Figure 5(B)) demonstrating that there are more shared species between these three sites in comparison to bushland thicket and bamboo habitat types. The upland Ericaceous moorland is the most dissimilar in terms of species composition between habitat types. The pattern is replicated with the analysis of dissimilarity between altitude zones with two branches separating zones above and below 2500m asl (Figure 5 A-C). 
370 Analysis of $\beta$-diversity patterns revealed a significant positive correlation between dung beetle pairwise community dissimilarity ( $\beta S \mathrm{SOR}$ ) and the Euclidean distance between transects (Mantel $\mathrm{r}^{2}=0.65, \mathrm{P}<0.05$ ) demonstrating that variation in communities was strongly and significantly related to their spatial distance. $\beta$-diversity partitioning between altitude zones showed that effects were mostly due to species turnover, which accounted for $91 \%$ of total variation compared to $4 \%$ for nestedness. $\beta$-diversity partitioning between forest types showed that effects were split between species turnover, which accounted for $64 \%$ of total variation and $87 \%$ for species nestedness indicating that species replacement (turnover) occurs at a much higher rate between altitude zones than between forest types.

\section{Discussion}

This study addressed the effects of landscape heterogeneity and altitude on dung beetle communities by comparing community dissimilarity, species diversity and species abundance among sites that varied in forest type and altitude. This study found no significant relationship between species richness and forest type but an interaction between the two factors plus a significant negative relationship between species richness and altitude which demonstrates $g$ that altitude in conjunction with forest type are the main factors in shaping dung beetle species composition in this Afromontane forest.

\section{Variation in community structure between habitat types on an altitudinal gradient}

Our results suggest the most important characteristic for determining community structure was mean canopy cover per forest type. A decrease in species richness was observed with increasing canopy cover but an increase in dung beetle abundance was detected in forest habitats with increased ground cover. The structure and complexity of forest canopies and understory vegetation can enact changes on local microclimatic conditions by causing changes in levels of radiant heat (Jay-Robert et al. 1997), light intensity and air and soil temperature. Many forest dung beetles are extremely sensitive to light intensity (Davis 2002) and as such may be restricted to either shaded or unshaded habitats. These differences may also be related to the temperature requirements of developing larvae. Halffter and Matthews (1966) suggested that 
the larvae of some species can only develop in shady forest habitats, whereas others will thrive in warm open pastures. Our results contrast those from previous studies conducted in the Neotropics (Pineda et al. 2005; Halffter et al. 2007; França et al. 2017). We found a greater number of species considered open vegetation specialists in comparison to forest specialists (Table 3).

Interestingly, comparisons may be drawn to the similarity in composition between temperate European dung beetle communities and those of the ANP. Both temperate and high-altitude dung beetle communities have a greater association with open vegetation and have demonstrated decreases in species richness as vegetation cover increases. The high proportion of tunnellers, the large number of individuals belonging to the genus Neocolobopterus in the Aphodiidae family, plus the paucity of roller species is more akin to a community found in a temperate ecosystem rather than an Afrotropical one. This undoubtedly is an altitudinal effect related to decreases in temperature and increases in rainfall found in high altitude montane areas (Byk and Piętka 2018). Similar findings in altitudinal replacement between the two main groups of dung beetles Aphodiini and Scarabaeinae (Lobo and Halffter 2000), have been reported from the mountainous areas of the Neotropics and the Afrotropics (Lobo and Davis 1999; Davis et al. 1999) and are similar to that which takes place along higher latitudes (Lobo, 2000). The cool-adapted species of Aphodiidae dominate the high altitude and species-poor temperate communities, while the warm-adapted Scarabaeinae species often dominate the low altitude and species-rich tropical communities (Escobar et al. 2005). We detected an almost complete absence of roller (telocoprid) species. This absence may be explained by telecoprid reproductive strategy, small body size (Hanski \& Cambefort 1991) and inability to maneuver dung resources within densely forested habitats. A weak, but significant, correlation between beetle abundance and ground cover suggests that dung beetle distribution may be affected by another factor namely soil type (Osberg et al. 1994; Davis 1997), with the degree of vegetative cover being of lesser importance. However, as soil identification in each habitat type was not undertaken for this study, this cannot be verified. 
421 Two species captured in open vegetation were not found in any of the Juniperus, Hagenia or Podocarpus 422 dominated forests, (Sisyphus sp1 and Copris algol), whilst one species, Catharsius sesostris was found to 423 be unique to forested sites. These three beetle species were found in low abundance ( $<8$ individuals) and were below the abundance threshold required by CLAM to conduct analyses. Of the 28 species used in CLAM, the majority of the dung beetles in the ANP are either restricted to closed canopy forest, or open vegetation that is located on the edges of forests and in glades, with few species inhabiting both (Table 3). Six of the eight species indicated as having strong associations with the habitat types studied are tunneling (paracoprid) dung beetles, with the remaining two, Neocolopterus kivuanus and Oniticellus planatus dweller (endocoprid). All eight species identified as indicators adhere to Caro's (2010) criteria for ecological disturbance indicator species in that their inventory, life history, and population forms a measurable temporal response to environmental change (Siddig et al. 2016). Onthophagus proteus and O. miricornis are considered regional endemics with a distribution likely centered around the Aberdare and Mount Kenya National Parks (D’Orbigny 1913). It is recommended that these species in particular be regarded as an ecological disturbance indicator and be used to monitor change in the health and distribution of habitats in the Aberdare National Park. However, very little is known about their dung preference (Stanbrook 2018) or the dispersal ability for these species and information on these traits would need to be collected to form part of a comprehensive future planning process.

\section{Biogeographical drivers of Afromontane dung beetle community composition}

439 Distinct differences in beetle abundance and species richness between open habitats and forested habitats 440 have been found repeatedly throughout the Neotropics (Estrada and Coates-Estrada 2002; Vulinec 2002).

441 Half of the dung beetle species which were found to be resident in forested habitats in the ANP belong to 442 the genus Onthophagus. Onthophagine dung beetles are ubiquitous across all habitats in Afrotropical forests 443 (Cambefort and Hanski 1991) and therefore their presence in large numbers in forested habitats in the ANP 
was expected. Onthophagines are generally smaller-bodied tunneller beetles that dig comparatively shallow nests and exist on a wide range of dung types (Davis et al. 2008). Over two thousand species of Onthophagines are currently described worldwide and the genus was determined to have diversified during the Oligocene, a diversification that coincided with the expansion of grasslands and the dispersal of mammals (Davis et al. 2002). Onthophagines were abundant in all habitats and across all elevation zones in the ANP up to $3800 \mathrm{~m}$ asl. However, in South America this genus is mostly restricted to habitats below $2000 \mathrm{~m}$ asl, with few species found at higher altitude on mountains (Zunino and Halffter 2007). The pattern of dung beetle species distribution clearly showed that the attenuation of dung beetle species richness at higher altitude zones is accompanied by species turnover, as species composition at low and high-altitude zones was largely different from that of mid-altitude zones. Numerous dung beetle species 'dropped out' with increasing elevation and were replaced by higher elevation specialists (e.g. Onthophagus proteus and species of the Neocolobopterus genera), resulting in little nestedness but high turnover. This type of high species compositional turnover along elevation gradients has been related to temperature and resource availability (Whittaker, 1956; MacArthur, 1972). High rates of turnover, as demonstrated here, have been documented for Central and South American (Alvarado et al. 2014) and African montane ecosystems (Gebert, Steffan-Dewenter, Moretto, \& Peters, 2019). The rate at which species are replaced on an altitudinal gradient is related to a number of factors acting at landscape scales down to the availability of microhabitats along the gradient. The ANP forms part of the Aberdare range which when formed during the Miocene (23-11 mya) was an isolated uplift (Scoon 2018b) and was almost entirely covered by savannah grassland (Pound et al. 2012). Many geologically older mountain tops exhibit a filtered, less diverse set of species which are phylogenetically related to those inhabiting lower elevations (Lobo and Halffter, 2000) and this may account for the high degree of nestedness between forest types on older mountain tops where the species composition of species-poor sites is a subset of the species-rich sites.

Mountain peaks experience widely contrasting ecological conditions in comparison to their surrounding lowlands. In their comprehensive global study of altitudinal variation in dung beetle assemblages on 
different mountains, Lobo and Halffter (2000) proposed two separate biological processes to explain the conformation of montane biota, the patterns of species richness and variations in community composition.

472 Firstly, vertical colonization defined as upland assemblages composed by species phylogenetically related with those inhabiting lowlands; and secondly, horizontal colonization defined as colonization of highland assemblages by lineages with a different evolutionary history and origin than those occupying lowlands. These processes as well as speciation are described as the drivers of mountain diversity (Lobo and Halffter, 2000b; Escobar et al., 2006; Arriaga-Jiménez et al., 2018). Biogeography is important in terms of ascertaining how dung beetle colonization occurred in the ANP. When the Aberdare mountain range was formed it was an isolated uplift, with its nearest neighbor being Mount Elgon, also newly formed, $350 \mathrm{~km}$ away (Scoon 2018a). Mount Kenya, its current closest highland block was not formed until the Pliocene Epoch, two million years later (Scoon 2018b). This makes it unlikely that horizontal colonization occurred due to the source population of Mount Elgon being at a greater distance than dung beetle dispersal capabilities allow, meaning that it is likely dung beetle species originally colonized the Aberdare range vertically, from the lowlands upwards. Lobo and Halffter (2000) outline two criteria that govern vertical colonization of dung beetles from lowlands: (1) vertically colonized mountain tops exhibit a filtered, less diverse set of species which are phylogenetically related to those inhabiting lower elevations; and (2) species richness decreases with increasing altitude as consequence of the environmental restrictions imposed on the fauna from warmer altitudes, especially in tropical regions (Janzen 1983). The most recent published dung beetle survey in the lowlands of the Aberdare range occurred at Mpala Ranch approximately $75 \mathrm{~km}$ away in 2002 (Gordon and Barbero 2008). A comparison of the species found at Mpala and those in the ANP reveal a limited overlap with seven species present in both locations, accounting for $23.5 \%$ of the species present in the ANP. These common species have an East African or Central West African distribution and are widespread in savannah habitat. With this in mind, and by meeting the criteria described above, it is likely that vertical colonization of the Aberdare range occurred as there is a significant overlap between lowland species and those found in the ANP. Also, 
the ANP dung beetle fauna does exhibit a notable decrease in species richness with altitude dropping from 29 species found at $\sim 2000 \mathrm{~m}$ to just 18 residents at elevations greater $3500 \mathrm{~m}$ asl (Appendix S2).

\section{Conservation implications}

Mountains are key environments for conservation of biodiversity during climatic change, providing refugia for species during postglacial cycles. Montane communities of dung beetles are important not only as historical and biographical reference points, and suppliers of values ecosystem services, but also as potential barometers of environmental change due to global warming. Global warming threatens montane dung beetle diversity by forcing species upslope, and reducing the space occupied by species specifically adapted to the cold or those that have limited thermal tolerance (Birkett et al. 2017). Any environmental change will cause local native populations to either adapt or migrate to avoid extirpation. Ectotherms are predicted to shift more rapidly in response to climate change than mammals (Paaijmans et al. 2013), due to having limited control of their body temperature compared to endothermic animals (Sheldon et al. 2011) and the unlinking of dung beetles and the food resources they depend upon may lead to declines and extinctions of Afromontane dung beetles in the future. Increased monitoring of dung beetle populations is urgently needed. Currently just 224 out of an estimated 7,500 species of sub-Saharan Scarabaeidae dung beetle have been assessed for inclusion in the Red List by the IUCN (www.iucn.org). We suggest those species whose distributions include montane ecosystems should take priority for future assessment for inclusion in future threatened species assessments. The increased conversion of available lowland habitats into commercial and agricultural small holdings and the upland shifting of these degraded habitats into montane lowland forest is expected. These impacts will effect montane species disproportionately as they become threatened with a loss of climate space and be pushed to the edge of their fundamental niche (Elsen and Tingley 2015).

Due to their biogeographical history and specialisms the dung beetles in Afromontane forest may be particularly negatively affected by temperature increases associated with global warming. Our results indicate that there is both intra- and interspecific variation in elevational placement and habitat preference 
of species and individuals. The upward shift in plant species, resulting in changes to habitat structure and even habitat loss is a well-documented occurrence in climate change literature (e.g. Thomas et al. 2004; Dirnböck et al. 2011); and will likely affect the dung beetle species in the ANP by pushing stenotypic species upwards into unsuitable habitat. Kohler and Maselli (2012) refer to mountains as early warning systems as they may provide an indication of the changes in species composition that lowland ecosystems can expect in the future due to climate change. Changes in the distribution of biota between lowlands and mountains in response to climate change are already widely documented (Gottfried et al. 2012; Menendez et al. 2014) and the use of dung beetles as indicators of environmental changes due to climate change is now growing (Menéndez and Gutiérrez 2004; Birkett et al. 2017). Results from a previous short study conducted in 1974 (Davis and Dewhurst, 1993) indicate while there was significant overlap between dung beetle species caught 40 years ago and the present day there were also seven species which were absent; Euoniticellus inequalis, Euoniticellus triangulates, Copris nepos, Onitis vanderkellini, two species in the genus Caccobius and Liatongus spathulatus. All of these species have climatic distributions centered around the wet highlands of East Africa (Davis and Dewhurst, 1993) and further work is urgently required to understand why these species are no longer detectable in the ANP.

The indicator species highlighted in this study should form a strong starting point for the instigation of a concerted management plan involving dung beetle distributional change in Afromontane ecosystems. Research exclusively focused on diversity patterns on tropical mountains at elevations higher than $2500 \mathrm{~m}$ asl are rare (Mastretta-Yanes et al. 2015) and rarer still for African mountains. This study specifically concentrates on the dung beetle fauna found in Afromontane forests and the compositional changes which occur along an altitudinal gradient. Our results have important conservation implications as they underscore the importance of preserving forest heterogeneity to maintain dung beetle diversity within mountain ecosystems. 


\section{References}

554 Aldrich M, Billington C, Edwards M, Laidlaw R (1997) Tropical montane cloud forests: an urgent priority for conservation. World Conserv Monit Cent 2:17.

Alvarado F, Escobar F, Montero-Muñoz J (2014) Diversity and biogeographical makeup of the dung beetle communities inhabiting two mountains in the Mexican Transition Zone. Org Divers Evol 14:105-114. https://doi.org/10.1007/s13127-013-0148-0

Arriaga-Jiménez A, Rös M, Halffter G (2018) High variability of dung beetle diversity patterns at four mountains of the Trans-Mexican Volcanic Belt. PeerJ 6:e4468. https://doi.org/10.7717/peerj.4468

Banks JE, Jackson C, Hannon LM, et al (2010) The cascading effects of elephant presence/absence on arthropods and an Afrotropical thrush in Arabuko-Sokoke Forest, Kenya. Afr J Ecol 48:1030-1038. https://doi.org/10.1111/j.1365-2028.2010.01211.x 
566

567

568

Bicknell JE, Phelps SP, Davies RG, et al (2014) Dung beetles as indicators for rapid impact assessments: Evaluating best practice forestry in the neotropics. Ecol Indic 43:154-161. https://doi.org/10.1016/j.ecolind.2014.02.030

Birkett AJ, Blackburn GA, Menendez R (2017) Linking species thermal tolerance to elevational range shifts in upland dung beetles. Ecography (Cop) 12:314-329. https://doi.org/10.1111/ecog.03458

Buddle CM, Beguin J, Bolduc E, et al (2012) The importance and use of taxon sampling curves for comparative biodiversity research with forest arthropod assemblages. Can Entomol 137:120-127. https://doi.org/10.4039/n04-040

Bussmann RW (2006) Vegetation zonation and nomenclature of African mountains - an overview. Lyonia $11: 41-66$

Byk A, Piętka J (2018) Dung beetles and their role in the nature. Eduk Biol i Środowiskowa 1:17-26. https://doi.org/10.24131/3247.180103

Cambefort Y, Hanski I (1991) Dung Beetle Ecology. Princeton University Press.

Cao Y, Epifanio J (2010) Quantifying the responses of macroinvertebrate assemblages to simulated stress: are more accurate similarity indices less useful? Methods Ecol Evol 1:380-388. https://doi.org/10.1111/j.2041-210X.2010.00040.x

Caro T (2010) Conservation by Proxy. Island Press.

Carpio C, Donoso D a., Ramón G, Dangles O (2009) Short term response of dung beetle communities to disturbance by road construction in the Ecuadorian Amazon. Ann la Société Entomol Fr 45:455-469. https://doi.org/10.1080/00379271.2009.10697629 
CEPF (2012) Eastern Afromontane Biodiversity Hotspot. Critical Ecosystem partnership Fund. BirdLife International.

Chao A (1984) On the Estimation of the Number of Classes in a Population. Board Found Scand J Stat 11:265-270. https://doi.org/10.1214/aoms/1177729949

Chazdon RL, Chao A, Colwell RK, et al (2011) A novel statistical method for classifying habitat generalists and specialists generalists and specialists. Ecology 92:1332-1343. https://doi.org/10.2307/23035004

Coe MJ (1969) Microclimate and animal life in the equatorial mountains. Zool Africana 4:101-128. https://doi.org/10.1080/00445096.1969.11447368

D’Orbigny H (1913) Synopsis des Onthophagides D’Afrique. Ann la Société Entomol Fr 82:1-743

Davis A (1997) Climatic and biogeographical associations of southern African dung beetles (Coleoptera: Scarabaeidae s. str.). Afr J Ecol 35:10-38. https://doi.org/10.1111/j.1365-2028.1997.051-89051.x

Davis AJ, Sutton SL (1998) The effects of rainforest canopy loss on arboreal; dung beetles in Borneo: implications for the measurement of biodiversity in derived tropical ecosystems. Divers Distrib 4:167-173

Davis AL., Frolov A V, Scholtz C (2008) The African Dung Beetle Genera, First Edit. Protea Brook House, Pretoria

Davis ALV, Dewhurst CF (1993a) Climatic and biogeographical associations of Kenyan and northern Tanzanian dung beetles (Coleoptera: Scarabaeidae). Afr J Ecol 31:290-305. https://doi.org/10.1111/j.1365-2028.1993.tb00543.x

Davis AL V. (2002) Dung beetle diversity in South Africa: Influential factors, conservation status, data inadequacies and survey design. African Entomol 10:53-65 
Davis AL V., Scholtz CH (2001) Historical vs. ecological factors influencing global patterns of scarabaeine dung beetle diversity. Diversity \& Distributions. 7:161-174. https://doi.org/10.1111/j.14724642.2001.00102.x

Davis AL V., Scholtz CH, Chown SL (1999) Species turnover, community boundaries and biogeographical composition of dung beetle assemblages across an altitudinal gradient in South Africa. J Biogeogr 26:1039-1055. https://doi.org/10.1046/j.1365-2699.1999.00335.x

Davis AL V., Scholtz CH, Philips TK (2002) Historical biogeography of scarabaeine dung beetles. J Biogeogr 29:1217-1256. https://doi.org/10.1046/j.1365-2699.2002.00776.x

Davis AL V, Dewhurst CF (1993b) Climatic and Biogepgraphical associations of Kenyan and Tanzanian dung beetles (Coleoptera: Scarabaeidae). Afr J Ecol 31:290-305

Dirnböck T, Essl F, Rabitsch W (2011) Disproportional risk for habitat loss of high-altitude endemic species under climate change. Glob Chang Biol 17:990-996. https://doi.org/10.1111/j.13652486.2010.02266.x

Eisenring M, Beck J, Agwanda B, et al (2016) Effects of habitat age and disturbance intensity on the biodiversity of three trophic levels in Central Kenya. Afr J Ecol 54:225-234. https://doi.org/10.1111/aje.12292

Elsen PR, Tingley MW (2015) Global mountain topography and the fate of montane species under climate change. Nat Clim Chang 5:772

Escobar F, Lobo JM, Halffter G (2005) Altitudinal variation of dung beetle (Scarabaeidae: Scarabaeinae) assemblages in the Colombian Andes. Glob Ecol Biogeogr 14:327-337. https://doi.org/10.1111/j.1466-822X.2005.00161.x

Escobar F, Lobo JM, Halffter G (2006) Assessing the origin of Neotropical mountain dung beetle 

assemblages (Scarabaeidae: Scarabaeinae): the comparative influence of vertical and horizontal colonization. J Biogeogr 33:1793-1803. https://doi.org/10.1111/j.1365-2699.2006.01528.x

Estrada A, Coates-estrada R (2002) Dung beetles in continuous forest, forest fragments and in an agricultural mosaic habitat island at Los Tuxtlas , Mexico

Fjeldsa J, Lovett JC (1997) Geographical patterns of old and young species in African forest biota: the significance of specific montane areas as evolutionary centres. Biodivers Conserv 6:325-346. https://doi.org/10.1023/a:1018356506390

França FM, Frazão FS, Korasaki V, et al (2017) Identifying thresholds of logging intensity on dung beetle communities to improve the sustainable management of Amazonian tropical forests. Biol Conserv 216:115-122. https://doi.org/10.1016/j.biocon.2017.10.014

Gebert F, Steffan-Dewenter I, Moretto P, Peters MK (2019) Climate rather than dung resources predict dung beetle abundance and diversity along elevational and land use gradients on Mt. Kilimanjaro. J Biogeogr 1-11. https://doi.org/10.1111/jbi.13710

Gordon RD, Barbero E (2008) Dung Beetles ( Coleoptera: Scarabaeidae : Scarabaeinae ) Of The Mpala Research Centre And Environs, Laikipia District, Kenya. J East African Nat Hist 97:135-164

Goslee S., Urban D. (2007) The ecodist package for dissimilarity-based analysis of ecological data. J Stat Softw 22:1-19

Gottfried M, Pauli H, Futschik A, et al (2012) Continent-wide response of mountain vegetation to climate change. Nat Clim Chang 2:111

Halffter G, Matthews E. (1966) The natural history of dung beetles of the subfamily Scarabaeinae. Folia Entomol Mex 12:1-312 
Halffter G, Pineda E, Arellano L, Escobar F (2007) Instability of Copronecrophagous Beetle Assemblages ( Coleoptera: Scarabaeinae ) in a Mountainous Tropical Landscape of Mexico. Environmental Entomology 36: 1397-1407. 10.1603/0046-225X(2007)

Hanski I, Cambefort Y (1991) Dung Beetle Ecology. Princeton University Press

Hanski I, Koskela H (1979) Resource partitioning in six guilds of dung-inhabiting beetles (Coleoptera). Annales Entomologici Fennici. 45:1-12.

Hedburg O (1969) Evolution and speciation in a tropical high mountain flora. Biol J Linn Soc 1:135-148. https://doi.org/10.1111/j.1095-8312.1969.tb01816.x

Jankowski JE, Ciecka AL, Meyer NY, Rabenold KN (2009) Beta diversity along environmental gradients: implications of habitat specialization in tropical montane landscapes. J Anim Ecol 78:315-327. https://doi.org/10.1111/j.1365-2656.2008.01487.x

Janzen DH (1983) Seasonal Change in Abundance of Large Nocturnal Dung Beetles (Scarabaeidae) in a Costa Rican Deciduous Forest and Adjacent Horse Pasture. Oikos 41:274. https://doi.org/10.2307/3544274

Jay-Robert P, Lobo JM, Lumaret J (1997) Altitudinal Turnover and Species Richness Variation in European Montane Dung Beetle Assemblages.Artic and Alpine Research 29:196-205

Kindt R, Breugel P van, Lillesø JPB, et al (2014) Potential natural vegetation of eastern Africa (Ethiopia, Kenya, Malawi, Rwanda, Tanzania, Uganda and Zambia): Volume 3: Description and tree species composition for woodland and wooded grassland potential natural vegetation types. For Landsc Work Pap 3:194pp

Kohler T, Maselli D (2012) Mountains and Climate Change - From Understanding to Action www.mountainpartnership.org 
Krell-Westerwalbesloh S, Krell FT, Linsenmair KE (2004) Diel separation of Afrotropical dung beetle guilds - Avoiding competition and neglecting resources (Coleoptera: Scarabaeoidea). J Nat Hist 38:2225-2249. https://doi.org/10.1080/00222930310001618921

Larsen TH, Forsyth A (2005) Trap spacing and transect design for dung beetle biodiversity studies. Biotropica 37:322-325. https://doi.org/10.1111/j.1744-7429.2005.00042.x

Laurance WF, Carolina Useche D, Shoo LP, et al (2011) Global warming, elevational ranges and the vulnerability of tropical biota. Biol Conserv 144:548-557. https://doi.org/10.1016/j.biocon.2010.10.010

Lobo JM, Davis AL V (1999) An intercontinental comparison of dung beetle diversity between two mediterranean-climatic regions: local versus regional and historical influence. Divers Distrib 5:91103

Lobo JM, Halffter G (2000) Biogeographical and Ecological Factors Affecting the Altitudinal Variation of Mountainous Communities of Coprophagous Beetles (Coleoptera: Scarabaeoidea): a Comparative Study. Ann Entomol Soc Am 93:115-126. https://doi.org/10.1603/0013-

Martin EH, Cavada N, Ndibalema VG, Rovero F (2015) Modelling fine-scale habitat associations of medium-to-large forest mammals in the Udzungwa Mountains of Tanzania using camera trapping. Trop Zool 6975:1-15. https://doi.org/10.1080/03946975.2015.1078568

Mastretta-Yanes A, Moreno-Letelier A, Piñero D, et al (2015) Biodiversity in the Mexican highlands and the interaction of geology, geography and climate within the Trans-Mexican Volcanic Belt. J Biogeogr 42:1586-1600. https://doi.org/10.1111/jbi.12546

Mayor JR, Sanders NJ, Classen AT, et al (2017) Elevation alters ecosystem properties across temperate treelines globally. Nature 542:91-95 
Menéndez R, Gonzalez-Megas A, Jay-Robert P, Marquez-Ferrando R (2014) Climate change and elevational range shifts: Evidence from dung beetles in two European mountain ranges. Glob Ecol Biogeogr 23:646-657. https://doi.org/10.1111/geb.12142

Menéndez R, Gutiérrez D (2004) Shifts in habitat associations of dung beetles in northern Spain: Climate change implications. Ecoscience 11:329-337. https://doi.org/10.1080/11956860.2004.11682840

Merckx VSFT, Hendriks KP, Beentjes KK, et al (2015) Evolution of endemism on a young tropical mountain. Nature. https://doi.org/10.1038/nature14949

Mittermeier RA, Turner WR, Larsen FW, et al (2011) Biodiversity Hotspots. In: Zachos FE, Habel JC (eds) Global Biodiversity Conservation: The Critical Role of Hotspots. Springer Berlin Heidelberg, Berlin, Heidelberg, pp 3-22

Nichols E, Larsen T, Spector S, et al (2007) Global dung beetle response to tropical forest modification and fragmentation: A quantitative literature review and meta-analysis. Biol Conserv 137:1-19. https://doi.org/10.1016/j.biocon.2007.01.023

Nichols E, Spector S, Louzada J, et al (2008) Ecological functions and ecosystem services provided by Scarabaeinae dung beetles. Biol Conserv 141:1461-1474. https://doi.org/10.1016/j.biocon.2008.04.011

Nichols E, Uriarte M, Bunker DE, et al (2013) Trait-dependent response of dung beetle populations to tropical forest conversion at local and regional scales. Ecology 94:180-189

Nyundo BA, Mtui A, Kissaka H (2006) An assessment of ecological and social-economic impacts caused by collection of deadwood, medicinal plants and cutting of grass for thatching in Udzungwa Mountains National Park. UMNP/WWF-TPO.

Oksanen J (2015) Vegan: an introduction to ordination. 1:1-10. https://doi.org/intro-vegan.Rnw 1260 2010- 
717

718

719

720

Osberg DC, Doube BM, Hanrahan SA (1994a) Habitat specificity in African dung beetles: the effect of soil type on the survival of dung beetle immatures (Coleoptera Scarabaeidae). Trop Zool 7:1-10. https://doi.org/10.1080/03946975.1994.10539236

Ostrom E (2008) International Forestry Resources and Institutions (IFRI).

Paaijmans KP, Heinig RL, Seliga RA, et al (2013) Temperature variation makes ectotherms more sensitive to climate change. Glob Chang Biol 19:2373-2380. https://doi.org/10.1111/gcb.12240

Paron P, Olago DO, Omuto CT (2013) Kenya: A Natural Outlook: Developoments in Earth Surface Processes, 1st Edition. Elsevier B.V., Oxford

Pineda E, Moreno C, Escobar F, Halffter G (2005) Frog, Bat, and Dung Beetle Diversity in the Cloud Forest and Coffee Agroecosystems of Veracruz . Conservation Biology 19:400-410

Pound MJ, Haywood AM, Salzmann U, Riding JB (2012) Global vegetation dynamics and latitudinal temperature gradients during the Mid to Late Miocene (15.97-5.33Ma). Earth-Science Rev 112:1-22. https://doi.org/10.1016/j.earscirev.2012.02.005

Pryke JS, Roets F, Samways MJ (2013) Importance of habitat heterogeneity in remnant patches for conserving dung beetles. Biodivers Conserv 22:2857-2873. https://doi.org/10.1007/s10531-013$0559-4$

Raine EH, Slade EM (2019) Dung beetle-mammal associations: Methods, research trends and future directions. Proc R Soc B Biol Sci 286:. https://doi.org/10.1098/rspb.2018.2002

Roggero A, Stanbrook R, Josso J (2017) Phylogenetic relationships of Epidrepanus within the subtribe Drepanocerina (Coleoptera: Scarabaeidae: Scarabaeinae: Oniticellini), with the description of two 
Rovero F, Owen N, Jones T, et al (2016) Camera trapping surveys of forest mammal communities in the Eastern Arc Mountains reveal generalized habitat and human disturbance responses. Biodivers Conserv 50-52. https://doi.org/10.1007/s10531-016-1288-2

Samways MJ (2015) Future-proofing insect diversity. Curr Opin Insect Sci 12:71-78. https://doi.org/10.1016/j.cois.2015.09.008

Scheffler PY (2005) Dung beetle (Coleoptera: Scarabaeidae) diversity and community structure across three disturbance regimes in eastern Amazonia. J Trop Ecol 21:9-19. https://doi.org/10.1017/S0266467404001683

Schmitt K (1992) Anthropo-zoogenic impact on the structure and regeneration of a submontane forest in Kenya. Tropical Forests 105-126. https://doi.org/10.1007/978-3-0348-7256-0_7

Scoon R (2018a) The Gregory Rift. In: Geology of National Parks of Central/Southern Kenya and Northern Tanzania,. Springer International Publishing, pp 39-57

Scoon R (2018b) Aberdare and Mount Kenya National Parks. In: Geology of National Parks of Central/Southern Kenya and Northern Tanzania,. Springer International Publishing, pp 91-101

Siddig AAH, Ellison AM, Ochs A, et al (2016) How do ecologists select and use indicator species to monitor ecological change? Insights from 14 years of publication in Ecological Indicators. Ecol Indic 60:223-230. https://doi.org/10.1016/j.ecolind.2015.06.036

Spector S, Ayzama S (2003) Rapid Turnover and Edge Effects in Dung Beetle Assemblages (Scarabaeidae) at a Bolivian Neotropical Forest-Savanna Ecotone1. Biotropica 35:394-404. https://doi.org/10.1111/j.1744-7429.2003.tb00593.x 
Stanbrook R (2018) The Scarabaeidae Dung Beetles of the Aberdare National Park, Republic Of Kenya: Ecosystem Services And Factors Affecting Diversity And Abundance. PhD thesis. Manchester Metropolitan University

Stanley WT, Kihaule PM (2016) Elevational distribution and ecology of small mammals on Tanzania's second highest mountain. PLoS One 11:1-15. https://doi.org/10.1371/journal.pone.0162009

Taylor SJ (2015) African biodiversity hotspots and other important conservation designations for unique areas which may include mountains African biodiversity hotspots and other important conservation designations for unique areas which may include mountains. Afromont. University of Pretoria

Thomas CD, Cameron A, Green RE, et al (2004) Extinction risk from climate change. Nature. 427:145148

Veech JA (2014) The pairwise approach to analysing species co-occurrence. J Biogeogr 41:. https://doi.org/10.1111/jbi.12318

Vulinec K (2002) Dung Beetle Communities and Seed Dispersal in Primary Forest and Disturbed Land in Amazonia. Biotropica 34:297-309

White F (1981) The history of the Afromontane archipelago and the scientific need for its conservation. Afr J Ecol 19:33-54. https://doi.org/10.1111/j.1365-2028.1981.tb00651.x

Wolda H (1987) Altitude, habitat and tropical insect diversity. Biol J Linn Soc 30:313-323. https://doi.org/10.1111/j.1095-8312.1987.tb00305.x

Zar J. (2010) Biostatistical Analysis, 5th Edition

Zunino M, Halffter G (2007) The association of Onthophagus Latreille, 1802 beetles (Coleoptera: Scarabaeinae) with vertebrate burrows and caves. Elytron 21:17-55 
780 Table 1 Alpha, Beta and Gamma diversity, Simpsons (H'); Simpsons $(\lambda)$ and Evenness (J') and Species

781 Richness estimators for each habitat type in the Aberdare National Park, Kenya

782

\begin{tabular}{|c|c|c|c|c|c|c|c|}
\hline \multirow{2}{*}{ Habitat type } & \multicolumn{3}{|c|}{ Diversity } & \multicolumn{3}{|c|}{ Indices } & \multirow{2}{*}{$\begin{array}{c}\text { Richness estimator } \\
\text { Chao } 1 \uparrow\end{array}$} \\
\hline & $\gamma$ & $\beta$ & $\alpha$ & $\mathrm{H}^{\prime}$ & $\lambda$ & $\mathrm{J}^{\prime}$ & \\
\hline Bushland Thicket & 32 & 1.63 & 21.43 & 2.94 & 0.922 & 0.828 & 36.87 \\
\hline $\begin{array}{c}\text { Juniper dominated } \\
\text { forest }\end{array}$ & 31 & 1.95 & 17.37 & 2.86 & 0.923 & 0.811 & 34.15 \\
\hline $\begin{array}{c}\text { Podocarpus } \\
\text { dominated forest }\end{array}$ & 32 & 2.05 & 15.56 & 2.85 & 0.925 & 0.823 & 32.11 \\
\hline Bamboo & 26 & 2.53 & 10.25 & 2.36 & 0.837 & 0.727 & 31.62 \\
\hline $\begin{array}{c}\text { Hagenia dominated } \\
\text { forest }\end{array}$ & 26 & 2.63 & 9.87 & 2.20 & 0.833 & 0.677 & 26.93 \\
\hline Ericaceous grassland & 19 & 3.14 & 5.56 & 2.00 & 0.808 & 0.68 & 22.75 \\
\hline
\end{tabular}

$\dagger($ Chao, 1984) 
789 Table 2 Results of a generalized linear model assessing dung beetle community Richness(A); Abundance

790 (B); and Shannon Index (C), for six habitats in the Aberdare National Park and five Altitude Zones (Z1-

791 Z5).

792

(A)Richness

\begin{tabular}{llllll}
\hline Source & Sum of Squares & DF & Mean Squares & F & P \\
\hline Habitat & 2609.39 & 3 & 652.35 & 35.56 & 0.083 \\
Altitude Zones & 126.02 & 4 & 42.01 & 2.290 & $<0.001$ \\
Habitat*Altitude Zones & 3314.06 & 88 & 22.156 & 16.14 & $<0.001$ \\
& & & & &
\end{tabular}

793

(B) Abundance

\begin{tabular}{llllll}
\hline Source & Sum of Squares & DF & Mean Squares & F & P \\
\hline Habitat & 19793 & 3 & 6598 & 0.180 & 0.909 \\
Altitude Zones & 619846 & 4 & 154962 & 4.229 & $<0.05$ \\
Habitat*Altitude Zones & 119546 & 88 & 95214 & 2.291 & $<0.01$ \\
\hline
\end{tabular}

794

(C) Shannon (H')

\begin{tabular}{llllll}
\hline Source & Sum of Squares & DF & Mean Squares & F & P \\
\hline Habitat & 0.9123 & 3 & 0.3041 & 2.1892 & 0.09 \\
Altitude Zones & 15.2140 & 4 & 3.8035 & 27.381 & $<0.001$ \\
Habitat*Altitude Zones & 9.3184 & 88 & 1.9414 & 16.58 & $<0.001$ \\
\hline
\end{tabular}

795

796

797 
Table 3 The results of CLAM analysis which assigned specialist or generalist status on the proportion of 799 individuals found in each vegetation type.

800

\begin{tabular}{lll}
\hline Generalist species & Open Vegetation species & Forest Specialist Species \\
\hline Copris atropolitus & Catharsius setostris & Caccobius sp \\
Helicopris neptunus & Copris morphaeus & Copris algol \\
Ixodina abyssinica & Copris sp2 & Euoniticellus intermedius \\
Onitis meyeri & Copris typhoeus & Neocolobterus kivuanus \\
Onitis parvulus & Diastellopalpus johnstonii & Onitis planatus \\
& Helicopris hunteri & Onthophagus nigriventris \\
& Liatongus arrowi & Onthophagus dochertyi \\
& Milichus picticollis & Onthophagus miricornis \\
& Neocolobopterus & Onthophagus sp2 \\
& maculicollis & \\
& Onthophagus filicornis & Onthophagus spurcatus \\
& Onthophagus proteus & \\
& Onthophagus spp1 & \\
& Proagoderus sexcornutus & \\
& &
\end{tabular}

801

802

803

804 
807 Fig 1 The location of the National Park in Kenya (a,b) and (c) the locations of vegetation transects and vegetation types within the Aberdare National Park. The altitude of each transect is indicated by red labels.

Fig 2 The study area showing boundary of the Aberdare National Park, Kenya and the distribution of the altitudinal zones found within the Aberdare NP. SRTM data was separated into 500m equidistant intervals to divide the Aberdare National Park into five elevation zones. Red dots represent transect locations. Yellow zone $=$ Z1, Light Green zone $=$ Z2, Dark Green zone =Z3, Blue zone $=$ Z4, Purple zone $=$ Z5.

Fig 3 Altitude as a predictor of dung beetle (a) abundance, (b) richness, and (c) diversity. The regression line is indicated in red, with the standard error of the mean plotted in grey.

Fig 4 Indicator species for each habitat using Pearson residuals derived from Chi Squared test of association. Positive residuals relate to positive associations, negative residuals relate to negative associations. Diasjohn: Diastellopalpus johnstonii; Milipict: Milichus picticollis; Neokivu: Neocolobopterus kivuanus; Onitplan: Oniticellus planatus; Onitanth: Onitis anthracinus; Onitmeyeri: Onitis meyeri; Onthmiri: Onthophagus miricornis; Onthprot: Onthophagus proteus.

Fig 5 Dendrograms showing the degree of dissimilarity in dung beetle beta diversity among (A) turnover (species replacement) in altitude zones B1 (1888-2000m asl), B2 (2001-2500m asl), B3 (2501-3000m asl), B4 (3001-3500m asl), and B5 (3501-4000m asl) and (B) habitats based on a cluster analyses using the Sørenson index. Nestedness (species subsets) between altitude bands is displayed in (C) and between habitat types in (D). The axis height of the dendrogram is $\beta$ values per habitat type or altitude band. 
830

831

832

833

834

835

836

837

838

839

840

841

842

843

844

845

846

847

848 


\section{Appendices}

Appendix S1: The number of Dung beetle species recorded per forest type in Aberdare NP, Kenya.

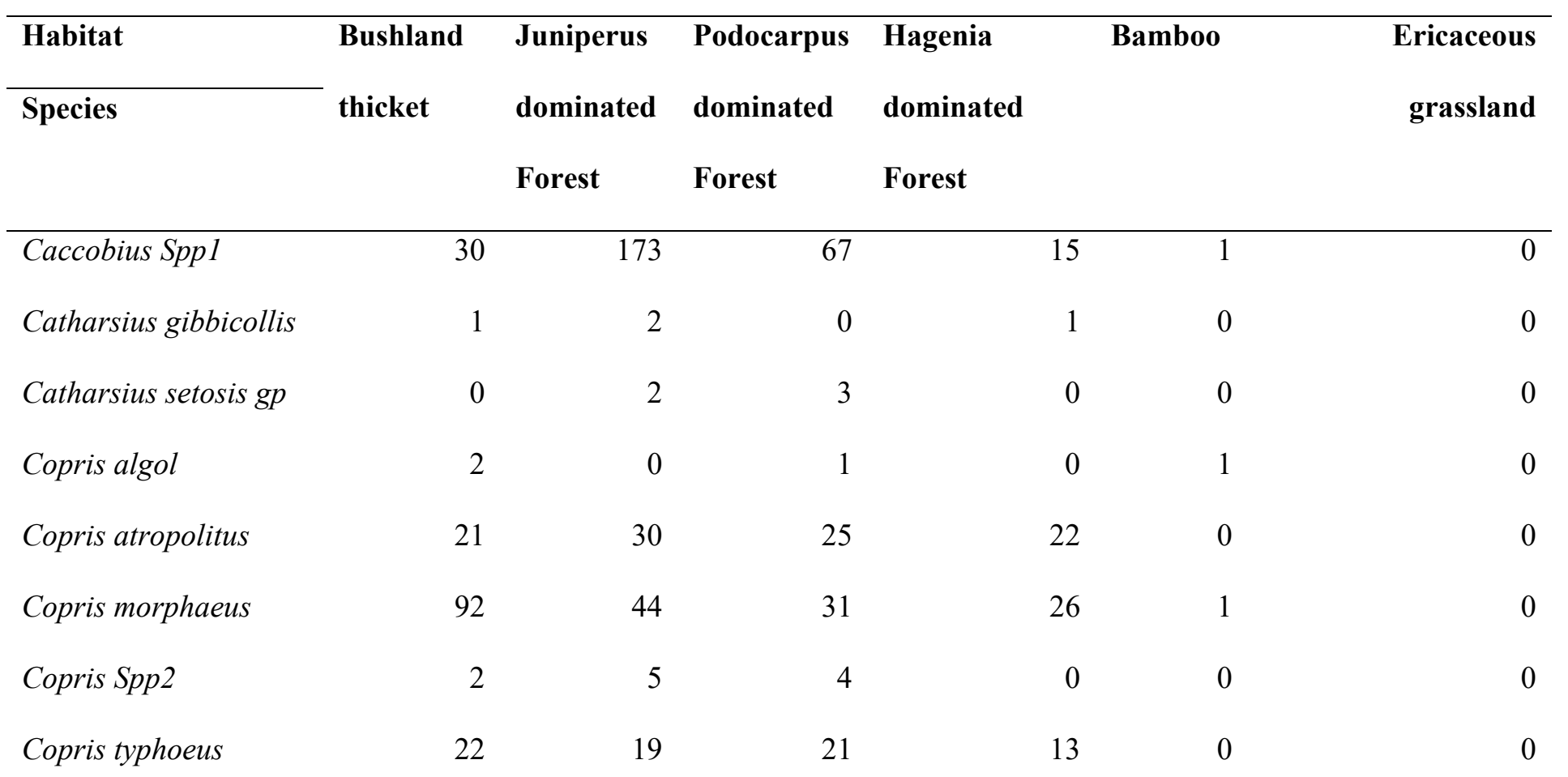


Diastellopalpus

johnstoni

Epidrepanus keniensis

Euoniticellus

intermedius

Heliocopris hunteri

Heliocopris neptunus

Heliocopris stroehli

Hetronitis ragazzi

Ixodina abysinnicus

Liatongus arrowi

Milichus picticollis

Neocolobopterus

kivuanus

Neocolobopterus

macaucollis

52
7

4

4

45

0

0

0

2

0

35

89

444

287

259

20
103

46
379

173

32

\section{0}

0

0

0

0

0

0

0

0

2

$0 \quad 0$

2

0 
Oniticellus planatus

Onitis anthracinus

Onitis meyeri

Onthophagis

nigriventis

Onthophagus proteus

Onthophagus

dochertyi

Onthophagus filicornis

Onthophagus

fimetarius

61

Onthophagus sppl
446
0
26

29

1

9 
Onthophagus

spurcatus

Proagoderus

sexcornutus

40

3

9

3

0

0

Sisyphus spl

5

0

0

0

0

0 
Appendix S2: Dung beetle abundance, species richness and diversity recorded per Altitude zone in Aberdare NP, Kenya

\begin{tabular}{|c|c|c|c|c|c|}
\hline Altitude Band & $\begin{array}{c}\text { Zone } 1 \\
\text { 1888-2000m }\end{array}$ & $\begin{array}{c}\text { Zone } 2 \\
\text { 2001-2500m }\end{array}$ & $\begin{array}{c}\text { Zone } 3 \\
\text { 2501-3000m }\end{array}$ & $\begin{array}{c}\text { Zone } 4 \\
\text { 3001-3500m }\end{array}$ & $\begin{array}{c}\text { Zone } 5 \\
\text { 3500-4000m }\end{array}$ \\
\hline Species & & & & & \\
\hline Caccobius n.sp & 73 & 543 & 15 & 32 & 0 \\
\hline $\begin{array}{l}\text { Catharsius } \\
\text { gibbicollis }\end{array}$ & 11 & 9 & 0 & 1 & 0 \\
\hline Catharsius setosis & 5 & 7 & 0 & 0 & 0 \\
\hline$g p$ & & & & & \\
\hline Copris algol & 6 & 152 & 6 & 8 & 13 \\
\hline Copris atropolitus & 14 & 101 & 10 & 25 & 9 \\
\hline Copris morphaeus & 19 & 189 & 10 & 33 & 1 \\
\hline Copris Spp2 & 18 & 99 & 13 & 50 & 1 \\
\hline Copris typhoeus & 14 & 99 & 15 & 16 & 9 \\
\hline $\begin{array}{l}\text { Diastellopalpus } \\
\text { johnstoni }\end{array}$ & 13 & 187 & 0 & 6 & 0 \\
\hline $\begin{array}{l}\text { Epidrepanus } \\
\text { keniensis n.sp }\end{array}$ & 1 & 4 & 0 & 0 & 0 \\
\hline $\begin{array}{l}\text { Euoniticellus } \\
\text { intermedius }\end{array}$ & 65 & 718 & 97 & 165 & 22 \\
\hline Heliocopris & 31 & 24 & 0 & 0 & 0 \\
\hline
\end{tabular}


Heliocopris

neptunus

Heliocopris

stroehli

Hetronitis ragazzi

Ixodina

abysinnicus

Milichus

picticollis

Neocolobopterus

kivuanus

Neocolobopterus

macaucollis

planatus

Onitis anthracinus

Onitis meyeri

Onitis parvvulus

Onthophagis

nigriventis

Onthophagus

proteus

Onthophagus

dochertyi 
Onthophagus

filicornis

Onthophagus

fimetarius

1096

193

703

Onthophagus

miricornis

Onthophagus sp1

50

144

13

19

13

Onthophagus sp2

201

802

38

49

0

Onthophagus

spurcatus

90

Proagoderus

sexcornutus

Sisyphus spl

4

0

Abundance

1881

10154

929

3150

727

Species Richness

33

34

24

26

Diversity (H') 